\title{
The incidence and management of workplace violence among medical professionals in the United States: A methodological pilot study
}

\author{
Ashleigh Chinelo Oguagha ${ }^{1,2}$, Jing Chen ${ }^{* 2}$ \\ ${ }^{1}$ School of Public Administration, Huazhong University of Science and Technology, China \\ ${ }^{2}$ School of Medicine and Health Management, Tongji Medical College, Huazhong University of Science and Technology, China
}

Received: November 7, 2018

DOI: $10.5430 /$ jha.v8n1p56
Accepted: January 24, 2019

Online Published: January 30, 2019

\begin{abstract}
This study aimed to investigate workplace violence (WPV) experienced by medical professionals in the United States as well as individual and managerial actions following violent episodes and further, predict estimators of WPV. A modified version of the Workplace Violence in the Health Sector: Country Case Studies Research Instruments Survey Questionnaire was used to assess the incidence and management of workplace violence experienced by healthcare workers. Medical personnel from two social aggregation websites were recruited to participate in an online survey. 226 valid questionnaires were received. $48.5 \%$ and $76.1 \%$ of respondents, respectively, experienced physical and psychological violence in the past year. Risk factors for violence included occupation, patient population, ethnicity, and higher levels of anxiety regarding violence in hospitals. Overall, 17.7\% of reported incidents were investigated, $52.4 \%$ of cases saw no consequences meted out to perpetrators and $51.7 \%$ of victims suffered from negative emotions or aftereffects following a violent episode. Only $30.1 \%$ of victims formally reported their experience with violence. The prevalence of violence was high and medical professionals were negatively affected by violence; however, formal reporting of episodes was low and measures combating violence were inadequate. Harsher penalties for perpetrators of violence are needed and hospitals need to implement guidelines that track the management of violence.
\end{abstract}

Key Words: Healthcare professionals, Workplace violence, Aggression, Hospital administration

\section{INTRODUCTION}

The Occupational Safety and Health Administration (OSHA) defines Workplace Violence (WPV) as "any act or threat of physical violence, harassment, intimidation, or other threatening disruptive behavior that occurs at the work site". ${ }^{[1]}$ WPV encompasses a variety of outcomes, consisting of physical violence and psychological violence, i.e., disruptive behavior expressed as bullying, harassment, coercion, verbal abuse, sexual harassment, and racial harassment. ${ }^{[2]}$ Because it occurs in all work environments and increases significantly in stressful situations, WPV is considered one of the leading occupational health and safety issues. ${ }^{[3]}$ Healthcare professionals are reported to experience the largest number of workplace assaults that involve a customer, patient, or other persons receiving services. ${ }^{[4]}$ In some cases, the discovered incidence rate of patient verbal and physical abuse against healthcare professionals was higher than the reported national average. ${ }^{[5]}$ Previous studies have shown that repeated

\footnotetext{
*Correspondence: Jing Chen; Email: chenjing@ mails.tjmu.edu.cn; Address: 13\# Hangkong Lu, Qiaokou District, Wuhan, Hubei Province, 430030, P. R. China.
} 
exposure physical and non-physical violence can result in emotional and physical symptoms such as distress, anxiety, stress, anger, fatigue, and exhaustion $;^{[2,6,7]}$ it also increases professional absenteeism and employee turnover. ${ }^{[8]}$ The bulk of research in the healthcare sector focuses solely on specific groups such as nurses, ${ }^{[9-12]}$ or specific departments such as high-risk wards ${ }^{[13]}$ and the emergency department. ${ }^{[11,12,14]}$

Ultimately, hospitals find it challenging to provide sufficient healthcare services while ensuring the physical and mental safety of their medical staff. This challenge is further exacerbated by society's need to receive services quickly. Due to the variation between studies and the vast number of underreported cases, there is a gap in comparative studies across healthcare departments and professional groups. Survey assessments reveal that less than $25 \%$ of WPV victims submit written reports following incidents of violence. ${ }^{[5,7,9,10]}$ The causes of the disparity in written reporting following violent incidents has yet to be adequately investigated. The aim of this study is to evaluate the one-year prevalence and characteristics of violence experienced by healthcare personnel in the United States as well as individual and managerial actions following violent incidents.

\section{Methods}

Workplace violence studies have been conducted over a number of years. Although numerous studies have explored the incidence and prevalence of workplace violence across various sectors, we wanted to explicitly explore predictors of violence as well as managerial actions taken after episodes. Because medical personnel in the US disproportionally experience WPV, we chose to pilot a study for healthcare professionals who have experienced violence initiated by patients and/or their families at their place of employment.

\subsection{Sampling measures}

A convenience sampling was utilized in which subjects were recruited through recruitment postings on Reddit.com and Allnurses.com. Both websites were chosen because they each target different demographics and have large pools of unique users. Reddit.com is the largest social aggregation website for the general populous whereas Allnurses.com is the largest online community and peer-based service for nurses and nursing students. Recruitment postings specifically targeted healthcare professional working in a hospital setting in the United States of America. All participants freely, voluntarily, and anonymously completed the survey. For the purpose of this study, healthcare occupational groups were divided into three categories: (1) the nurse occupational grouping consisted of nurses and nurse's aides, (2) the physician occupational grouping consisted of physicians, nurse

Published by Sciedu Press practitioners and physician's assistants, and (3) the other occupational grouping included all others who worked at the hospital and had contact with patients. The Ethics Committee of Tongji Medical College, Huazhong University of Science and Technology approved this research. The study was conducted from January 2017 until April 2017.

\subsection{Study instrument}

The questionnaire used in this study was developed from a pre-validated tool, the "ILO/ICN/WHO/PSI Workplace Violence in the Health Sector: Country Case Studies Survey Questionnaire", which was created and published to explore the prevalence of violence in the healthcare sector for respondents in English speaking countries. ${ }^{[15]}$ For the purpose of this study the Personal and Workplace Data, Physical Workplace Violence, Psychological Workplace Violence, and Hospital sections were utilized. The personal information section was adapted to include and/or amend information on ethnicity, educational background, occupational title/responsibilities, and geographical region. Additionally, three opened questions regarding respondents' opinions on the contributing factors of physical violence and psychological (non-physical) violence in the hospital as well as important measures that would reduce violence were included. A virtual version of the questionnaire was hosted by Surveymonkey.com and required an estimated 10 to 15 minutes to complete.

Physical and psychological violence were used as indicators of violence. Physical violence was described as violence that occurs when someone uses a part of his or her body or an object to control, humiliate, or degrade a person. Two types of psychological violence were investigated: verbal abuse and racial harassment. Verbal abuse occurs when someone uses either spoken or non-spoken language to harm an individual. Cultural/Racial Harassment occurs when an individual is harmed as a result of their skin color or practices that are part of their culture, religion and/or tradition.

\subsection{Data analysis}

Statistical analyses were performed using SPSS version 20.0. Descriptive statistics were used to identify participant demographics, the characteristics and frequency of reported incidents as well as respondent and managerial actions following violent episodes. Chi-squared analyses were used to examine the relationship between demographic characteristics and violence exposure. Separate logistic regression analyses using a backward stepwise approach was used to determine the predictors of physical and psychological violence. Multicollinearity among predictors was tested using collinearity diagnostics, including correlational analysis be- 
tween variables, tolerance and variance inflation factors. For all statistical tests, a $p$ value of less than .05 was considered statistically significant and a $p$ value of less than .10 was a criterion for removal from regression models.

Table 1. Participant Demographic

\begin{tabular}{|c|c|c|}
\hline Characteristics & No $(\%)$ & $\%$ \\
\hline \multicolumn{3}{|l|}{ Gender } \\
\hline Female & $178 / 226$ & 78.8 \\
\hline Male & $43 / 226$ & 19.0 \\
\hline Prefer not to answer & $5 / 226$ & 2.2 \\
\hline \multicolumn{3}{|l|}{ Ethnicity } \\
\hline White/Caucasian & $178 / 226$ & 78.8 \\
\hline Black/African American & $21 / 226$ & 9.3 \\
\hline Asian/pacific islander & $11 / 226$ & 4.9 \\
\hline Other & $16 / 226$ & 7.1 \\
\hline \multicolumn{3}{|l|}{ Age groups } \\
\hline $20-34$ & $105 / 226$ & 46.5 \\
\hline $35-49$ & $71 / 226$ & 31.4 \\
\hline $50+$ & $50 / 226$ & 22.1 \\
\hline \multicolumn{3}{|l|}{ Educational Level } \\
\hline Less than four year degree & $56 / 224$ & 25.0 \\
\hline Bachelor’s degree & $120 / 224$ & 53.6 \\
\hline Post graduate degree & $48 / 224$ & 21.4 \\
\hline \multicolumn{3}{|l|}{ Hospital Classification } \\
\hline Trauma Level I & $84 / 205$ & 41.0 \\
\hline Trauma Level II & $36 / 205$ & 17.6 \\
\hline Trauma Level III & $31 / 205$ & 15.1 \\
\hline Trauma Level IV/V & $22 / 205$ & 10.7 \\
\hline Unknown & $32 / 205$ & 15.6 \\
\hline \multicolumn{3}{|l|}{ Department } \\
\hline General medicine & $43 / 204$ & 21.1 \\
\hline High-risk wards & $52 / 204$ & 25.5 \\
\hline Intensive care unit & $28 / 204$ & 13.7 \\
\hline Specialized departments & $38 / 204$ & 18.6 \\
\hline Other & $43 / 204$ & 21.1 \\
\hline \multicolumn{3}{|l|}{ Over-night shifts per month } \\
\hline None & $51 / 204$ & 25 \\
\hline 1-4 times & $44 / 204$ & 21.6 \\
\hline 5-8 times & $22 / 204$ & 10.8 \\
\hline 8+ times & $87 / 204$ & 42.6 \\
\hline \multicolumn{3}{|l|}{ Job Status } \\
\hline Full-time: Yes & $172 / 205$ & 83.9 \\
\hline \multicolumn{3}{|l|}{ Managerial duties } \\
\hline Yes & $40 / 204$ & 19.6 \\
\hline \multicolumn{3}{|l|}{ Staff in same area } \\
\hline Less than 5 & $81 / 204$ & 39.7 \\
\hline $6-10$ & $77 / 204$ & 37.7 \\
\hline $11+$ & $46 / 204$ & 22.5 \\
\hline \multicolumn{3}{|l|}{ Sex of patient } \\
\hline Male & $8 / 204$ & 3.9 \\
\hline Female & $16 / 204$ & 7.8 \\
\hline Both & $180 / 204$ & 88.2 \\
\hline
\end{tabular}

\section{RESUlts}

The questionnaire was started by 269 healthcare professionals; 226 were returned completed, for an effective response rate of $84.0 \%$. The study of healthcare professionals consisted of mostly women and those that identified as White/Caucasian (see Table 1). Bachelor's degree holding respondents as well as those aged 20-34 accounted for approximately half of the sample. Occupationally, nurses and those that had less than five years' working experience at their present hospital accounted for $83.6 \%$ and $69.1 \%$ of the participants. $25.5 \%$ of participants worked on a high-risk unit (e.g., emergency, psychiatry, surgery) and $41 \%$ worked in trauma Level I hospitals. Most respondents reported having less than five years' experience practicing medicine, being in non-managerial positions and having full-time employee job status (see Table 1). Lastly, the majority of healthcare professionals in this study reported working with patients of both sexes (see Table 1) as well as adult and elderly patient populations (see Table 2).

\subsection{Prevalence and characteristics of WPV}

Analysis revealed that the individual prevalence rates of physical and psychological violence were $48.5 \%$ and $76.1 \%$, respectively. The majority of the respondents reported experiencing more than five episodes of WPV per month (see Table 3). Although only $5.5 \%$ of physical attacks occurred with a weapon, $31 \%$ of respondents attacked were injured. Table 2 illustrates the statistically significant differences in the prevalence rate of workplace violence among participant characteristics. Nurses when compared to nonnurses had a higher incidence of both types of violence. Medical personnel with less than five years' experience practicing medicine reported the highest prevalence of physical violence whereas respondents with 1-5 years' work experience at their current hospital reported the highest prevalence of psychological violence. The incidence rate of physical violence among patient populations was highest for respondents working with elderly patients and lowest for those working with newborn patients had a low incidence rate. Comparatively, the prevalence of psychological violence among those working with elderly patients was not significant. However, medical staff working with newborns and adults had higher incidence of psychological violence compared to those who did not work with those patient populations. In both types of violence, the incidence rate according to those who were worried to some degree about violence in their hospital was $52.0 \%$ for physical violence and $82.6 \%$ for psychological violence. No significant difference was found among gender, age, ethnicity, region, marital status, education level, department, managerial responsibilities, job status, monthly over-night shift, patient sex, hospital setting or staff numbers according 
to violence experienced by medical staff.

\subsection{Reporting and managing violent incidents}

Table 3 shows the characteristics of violent incidents as well as actions taken by victims and management following an episode of violence. Patients were reported to be the main perpetrators of violence. The majority of victims responded by telling a family member, friend, or colleague about the attack followed by verbally telling their attacker to stop and formally reporting the incident to a senior staff member. $58.1 \%$ and $65.0 \%$ of those who did not report their experience with physical or psychological violence indicated that reporting the incident was useless/not important. The remainder of the participants indicated that they were afraid of negative consequences stemming from the report (physical violence, 9.7\%; psychological violence, $11.4 \%$ ) or listed another explanation for not reporting (physical violence, $32.3 \%$; psychological violence, $23.6 \%$ ). Over half of the participants were satisfied to some degree with the way their physical incident was handled $(55.3 \%)$. The majority of the respondents were dissatisfied to some degree with the way their psychological abuse was handled (57.4\%).

Table 2. Prevalence of Workplace Violence according to Participant Characteristics

\begin{tabular}{|c|c|c|c|c|c|c|c|}
\hline \multirow{2}{*}{ Demographics } & \multirow{2}{*}{ Total } & \multicolumn{3}{|c|}{ Physical Violence } & \multicolumn{3}{|c|}{ Psychological Violence } \\
\hline & & $\mathbf{N}(\%)$ & $\chi^{2}$ & $p$ & $\mathbf{N}(\%)$ & $\chi^{2}$ & $p$ \\
\hline Occupation & & & 9.882 & $.002 *$ & & 8.399 & $.004 *$ \\
\hline Nurse/Nurse’s aide & 189 & $88(53.3)$ & & & 118 (80.3) & & \\
\hline Physicians/NP/PA/Others & 37 & $7(22.6)$ & & & $16(55.2)$ & & \\
\hline \multicolumn{8}{|l|}{ Patient type $\dagger$} \\
\hline Newborns & 24 & $5(22.7)$ & 6.575 & $.010^{*}$ & $12(57.1)$ & 4.735 & $.030 * *$ \\
\hline Infants & 29 & $12(44.4)$ & .203 & .652 & $16(61.5)$ & 3.578 & .059 \\
\hline Children & 37 & $18(50.0)$ & .041 & .839 & $22(64.7)$ & 3.030 & .082 \\
\hline Adolescents & 50 & $24(49.0)$ & .007 & .934 & $31(67.4)$ & 2.621 & .105 \\
\hline Adults & 177 & 79 (46.7) & 1.460 & .227 & 120 (78.9) & 4.848 & $.028 * *$ \\
\hline Elderly & 159 & $82(53.9)$ & 8.135 & $.004 *$ & $103(77.4)$ & .512 & .474 \\
\hline Years of Employment & & & .177 & .916 & & 6.260 & $.044 * *$ \\
\hline Under 1 year & 50 & $20(47.6)$ & & & $23(62.2)$ & & \\
\hline $1-5$ years & 104 & $46(50.0)$ & & & $69(83.1)$ & & \\
\hline $6+$ years & 69 & $28(46.7)$ & & & 41 (75.9) & & \\
\hline Years of Medical Experience & & & 7.871 & $.049 * *$ & & 1.115 & .774 \\
\hline Under 1 year & 29 & $10(41.7)$ & & & $16(69.6)$ & & \\
\hline $1-5$ years & 79 & $42(59.2)$ & & & 47 (78.3) & & \\
\hline $6-15$ years & 65 & $28(50.0)$ & & & $41(78.8)$ & & \\
\hline $16+$ years & 53 & 15 (33.3) & & & $30(73.2)$ & & \\
\hline Anxiety Level & & & 8.422 & $.038 * *$ & & 13.160 & $.004 *$ \\
\hline Not worried at all & 73 & $29(42.0)$ & & & 39 (63.9) & & \\
\hline Slightly Worried & 63 & $25(40.3)$ & & & $42(73.7)$ & & \\
\hline Moderately Worried & 56 & $33(62.3)$ & & & $42(89.4)$ & & \\
\hline Very Worried & 13 & $8(66.7)$ & & & $11(100)$ & & \\
\hline
\end{tabular}

†Participants were able to choose more than one answer; $* p<.01$ and $* * p<.05$

\subsection{Aftereffects of violent episodes}

A third of respondents who experienced physical violence were injured during the attack (see Table 3). In total, over half of the participants suffered from obsessive memories or thoughts, topic avoidance, heightened awareness and feeling burdened following any type of violent incident $(51.7 \%)$. In the majority of those case, the perpetrator of violence received no or unknown consequences (see Table 3). Overall, $21.4 \%$ of respondents affected by violence were offered counseling, speaking opportunities, or other support oppor- tunities following an incident. Victims of physical violence compared to victims of psychological violence were given more offers of support following an episode of violence.

\subsection{Predictors of workplace violence}

Separate regression models were fitted for possible variables associated with either type of workplace violence (see Table 4). Occupation, patient population (newborns and elderly), monthly over-night shifts, as well as the number of years practicing medicine were all found to have a relationship 
with physical violence. Ethnicity, occupation, and patient population (newborns and adults) were all found to have a relationship with psychological violence. No collinearity was found therefore significantly associated variables were all initially entered into their associated logistic regression models. The full adjusted models for physical violence and psychological violence were significant with a nonsignificant Hosmer and Lemeshow tests of $\chi^{2}=11.19, p=.08$ and $\chi^{2}=1.189, p=.76$, respectively. $63.1 \%$ of the sample was correctly classified by the physical violence final model, while $76.7 \%$ of the sample was correctly classified by the psychological violence final model.

Table 3. Reporting, Management and Aftereffects of WPV

\begin{tabular}{|c|c|c|c|c|}
\hline & $\mathbf{N}^{\#}$ & $\begin{array}{l}\text { Physical } \\
\text { Violence }\end{array}$ & $\mathbf{N}^{\#}$ & $\begin{array}{c}\text { Psychological } \\
\text { Violence }\end{array}$ \\
\hline Experienced Violence & 196 & $95(48.5)$ & 176 & $134(76.1)$ \\
\hline Frequency of Violence & 88 & & 130 & \\
\hline Once & & $4(4.5)$ & & $13(10.0)$ \\
\hline 2-4 times & & $33(37.5)$ & & $55(42.3)$ \\
\hline $5+$ times & & $51(58.0)$ & & $62(47.7)$ \\
\hline Type of aggressor & 91 & & 130 & \\
\hline Patient & & $78(85.7)$ & & $65(50)$ \\
\hline Family/friend of patient & & $7(7.7)$ & & $23(17.7)$ \\
\hline Both & & $6(6.6)$ & & $42(32.3)$ \\
\hline Injured & 91 & $28(30.8)$ & - & - \\
\hline Staff actions after incident* & 284 & & 364 & \\
\hline No action & & $6(2.1)$ & & $46(12.6)$ \\
\hline Physically defend self & & $27(9.5)$ & & - \\
\hline Told the person to stop & & $61(21.5)$ & & $91(25.0)$ \\
\hline Informally told another person (i.e. family, friend, co-worker) & & $71(25.0)$ & & $109(30.0)$ \\
\hline Reported it to a senior staff member & & $55(19.4)$ & & $71(19.5)$ \\
\hline Completed incident form & & $46(16.2)$ & & $23(6.3)$ \\
\hline Other & & $18(6.3)$ & & $27(7.4)$ \\
\hline Incident investigated & 83 & $22(53.6)$ & 130 & $18(13.8)$ \\
\hline Incident was preventable & 80 & $37(46.3)$ & 129 & $47(20.8)$ \\
\hline \multicolumn{5}{|l|}{ Aftereffects of violence } \\
\hline Obsessive memories or thoughts & 83 & $31(37.4)$ & 129 & $69(53.5)$ \\
\hline Topic Avoidance & 83 & $26(31.3)$ & 129 & $55(42.6)$ \\
\hline Super-alert or on guard & 82 & $63(76.8)$ & 128 & $78(60.2)$ \\
\hline Feeling like everything you did was an effort & 82 & $33(40.2)$ & 129 & $56(43.4)$ \\
\hline \multicolumn{5}{|l|}{ Offers of Support after incident } \\
\hline Counseling & 80 & $10(12.5)$ & 127 & $9(7.1)$ \\
\hline Opportunities to speak about it & 80 & $42(52.5)$ & 127 & 49 (38.6) \\
\hline Other support & 77 & $19(24.7)$ & 127 & $23(18.1)$ \\
\hline Consequences for attacker** & 30 & & 21 & \\
\hline None/unknown & & $15(50.0)$ & & $13(61.9)$ \\
\hline Verbal warning & & $3(10.0)$ & & $6(28.6)$ \\
\hline Asked to leave hospital & & $2(6.7)$ & & $1(4.8)$ \\
\hline Reported to police & & $5(16.7)$ & & - \\
\hline Other & & $5(16.7)$ & & $1(4.8)$ \\
\hline
\end{tabular}

Note. $\mathrm{N}^{*}$ represents the total number of responses; *Participants were able to choose more than one type of action following an incident of violence; **Participants were abl to choose more than one reason for not reporting violence 
A backward stepwise approach removed the variables monthly over-night shifts years of medical practice from the physical violence model. Ethnicity and patient type (newborns) were removed from the psychological violence model. Occupationally, nurses were approximately four times as likely to have experienced physical and psychological violence compared to other healthcare professionals. Working with newborn patients was not a significant predictor of physical violence however, respondents working with elderly patients were 2.4 times as likely to experience physical violence. Additionally, healthcare personnel working with adult patients were approximately four times as likely to experience psychological violence.

Table 4. Predictors of Physical and Psychological Violence using Logistic Regression Models

\begin{tabular}{|c|c|c|c|c|}
\hline $\begin{array}{l}\text { Dependent } \\
\text { Variable }\end{array}$ & Predictors & $\begin{array}{l}\text { Crude Odds Ratio } \\
\text { (95\% CI) }\end{array}$ & $\begin{array}{l}\text { Full Adjusted Odds Ratio } \\
\qquad(95 \% \mathrm{CI})\end{array}$ & $\begin{array}{l}\text { Final Adjusted Odds } \\
\text { Ratio (95\% CI) }\end{array}$ \\
\hline \multirow{17}{*}{$\begin{array}{l}\text { Physical } \\
\text { violence }\end{array}$} & Nurse & $3.88(1.44 \sim 10.45)$ & $4.14(1.60 \sim 10.70)$ & $4.19(1.68 \sim 10.46)$ \\
\hline & \multicolumn{4}{|l|}{ Patient type } \\
\hline & Non Newborns & 1.0 & 1.0 & 1.0 \\
\hline & Newborns & $0.34(0.11 \sim 1.08)$ & $0.36(0.12 \sim 1.15)$ & $0.40(0.13 \sim 1.21)$ \\
\hline & Non Elderly & 1.0 & 1.0 & 1.0 \\
\hline & Elderly & $2.34(1.04 \sim 5.24)$ & $2.32(1.05 \sim 5.15)$ & $2.44(1.12 \sim 5.30)$ \\
\hline & \multicolumn{4}{|c|}{ Years of Medical Experience } \\
\hline & Under 1 year & 1.0 & 1.0 & \\
\hline & $1-5$ years & $2.38(0.89 \sim 6.35)$ & $2.22(0.84 \sim 5.87)$ & \\
\hline & $6-15$ years & $2.07(0.73 \sim 5.86)$ & $2.07(0.74 \sim 5.81)$ & \\
\hline & $16+$ years & $1.14(0.38 \sim 3.39)$ & $1.08(0.37 \sim 3.17)$ & \\
\hline & \multicolumn{4}{|c|}{ Over-night shifts per month } \\
\hline & None & 1.0 & & \\
\hline & $1-4$ & $2.06(0.81 \sim 5.24)$ & & \\
\hline & $5-8$ & $2.53(0.80 \sim 8.02)$ & & \\
\hline & $8+$ & $1.67(0.75 \sim 3.75)$ & & \\
\hline & Model fit & $\chi^{2}=30.76, p=.00$ & $\chi^{2}=27.25, p=.00$ & $\chi^{2}=22.22, p=.00$ \\
\hline \multirow{12}{*}{$\begin{array}{l}\text { Psychological } \\
\text { violence }\end{array}$} & Nurse & $3.78(1.51 \sim 9.47)$ & $4.03(1.67 \sim 9.71)$ & $4.12(1.72 \sim 9.84)$ \\
\hline & \multicolumn{4}{|l|}{ Patient type } \\
\hline & Non Newborns & 1.0 & 1.0 & \\
\hline & Newborns & $0.44(0.15 \sim 1.27)$ & $0.48(0.17 \sim 1.33)$ & \\
\hline & Non Adults & 1.0 & 1.0 & 1.0 \\
\hline & Adults & $3.13(1.15 \sim 8.47)$ & $2.97(1.11 \sim 7.97)$ & $3.56(1.39 \sim 9.13)$ \\
\hline & \multicolumn{4}{|l|}{ Ethnicity } \\
\hline & White/Caucasian & 1.0 & & \\
\hline & Black/African American & $0.57(0.18 \sim 1.78)$ & & \\
\hline & Asian/Pacific Islander & $0.77(0.17 \sim 3.39)$ & & \\
\hline & Other & $0.26(0.01 \sim 1.00)$ & & \\
\hline & Model fit & $\chi^{2}=20.26, p=.002$ & $\chi^{2}=16.12, p=.001$ & $\chi^{2}=14.18, p=.0001$ \\
\hline
\end{tabular}

\section{Discussion}

This pilot evaluation of WPV experienced by our limited nonrepresentative sample of healthcare professionals revealed that a substantial percentage $(70.4 \%)$ of participants reported experiencing at least one incident of any type of violence in a 12-month period. International studies have shown that the overall prevalence of violence varied from $12.1 \%$ to $89 \%$, with the rate of psychical violence $(7 \%-68 \%)$ being lower than that of verbal violence $(19.6 \%-83 \%){ }^{[3,6,7,10,13,16-20]}$ Studies conducted on hospitals systems ${ }^{[14]}$ and those that 
amended the categorization of workplace violence verbal violence, physical violence, threats ${ }^{[7,14,18]}$ and sexual harassment ${ }^{[3,8]}$ had lower incidences of workplace violence than the present study. This suggests that the categorization of hospitals and violence are both determinants that affect workplace violence.

Consistent with other research, ${ }^{[7,13,19,21]}$ regression analysis showed that nurses had the highest risk of both types of violence. These results could be used as a hypothetical basis for future studies involving American nurses. Other studies have shown that factors such as gender and occupational status make U.S. nurses more likely to suffer from patient and/or customer related violence compared to nurses in other countries. ${ }^{[6,10-13]}$ Results also indicated that the likelihood of healthcare professionals', in our limited sample, experiencing violence was influenced by patient type. Working with older patients significantly increased the risk of violence whereas working with younger patients significantly decreased the odds of violence. ${ }^{[18]}$ Possible explanations include individual factors such as mental well-being and substance abuse problems. A study of patient aggression found that psychiatric disorders such as Alzheimer's, dementia and delirium are often seen in older patients who are physically and verbally combative. ${ }^{[22]}$ Additional studies on patient aggression in medical settings found that there is a relationship between drug/alcohol misuse and patient aggression ${ }^{[23]}$ as well as psychiatric syndromes and agression. ${ }^{[14,21,23]}$

Medical respondents' stress or anxiety about violence in the workplace could also be influencing their exposure to violence. Healthcare professionals in this study who were moderately or very worried about violence experienced a higher incidence of physical and psychological violence. An individual's increasing anxiety about violence is often reported as a pattern linked to violence. ${ }^{[20,24]}$ This could be because those who are more worried about violence may be more sensitive to patient dialogue thereby possibly misconstruing patient intentions and verbal cues.

Approaches used by participants to address workplace violence can be segregated into four categories. Formal written reporting via reports to senior management and completion of incident forms constitutes the first group: appropriate action. Results show that victims of both types of violence choose to report the incident to a senior staff member; however, twice as many victims of physical violence choose to complete incident forms than victims of psychological violence. Although psychological violence is often seen as the precursor to more severe forms of violence, ${ }^{[10]}$ it is harder to report because it is not as easy to document as physical violence. The second group constitutes comforting actions such as discussing the events with a family member, friend, or colleague. Few respondents noted the patient's violent behavior in their chart after experiencing aggression; instead, they preferred to informally tell a colleague, friend or family member about the incident. Healthcare professionals view violence as an accepted part of their job ${ }^{[6]}$ and conversations between colleagues could act as a means of stress relief or represent commiseration between co-workers.

The third group consists of verbal and/or physical defensive actions such as telling the aggressor to stop and physically defending oneself. Research shows that informal actions were more common than formal actions following a violent incident. ${ }^{[6,9]}$ The last group consisted of no employed actions; this was the reaction of $11.7 \%$ of victims. Many of which failed to take action because of negative feelings associated with the reporting process and an accepted culture of violence. Additionally, low levels of reported managerial responses to violent episodes could be deterring victims from reporting incidents. Research has shown that employing a designated officer that resolves violence-related issues in addition to better management of reporting and preventing violence could improve reporting numbers. ${ }^{[10]}$

Few respondents in this study reported being physically injured, needing to take days off following a physical encounter, or instances in which the attacker used a weapon, however a moderate number of respondents indicated feeling adverse psychological effects following incidents of violence. As mentioned in this study and others, victims of violence can experience obsessive memories, feelings of avoidance, and emotional exhaustion. ${ }^{[19]}$ Violence also affects employee turnover as well as job performance, and staff morale; ${ }^{[8]}$ all of which if left unchecked, can affect respondents' ability to diagnosis and treat patients. The lack of physical damages and instances involving weapons could be the result of the prohibition of weapons and drugs on hospital premises as well as increased security ${ }^{[11]}$ and metal detectors. ${ }^{[21]} \mathrm{Al}-$ though effective at deterring physical violence and incidents involving weapons, these measures do not address repeat offenders and perpetrators of psychological violence. $\mathrm{Re}$ search has shown that abusive prescription drug use and a patient's history of mental issue are two factors that are related to verbally abusive behavior. ${ }^{[23]}$ Hospitals should employ screening tools that would allow management staff to automatically identify repeat offenders and patients with mental illness and manage them through methods such as restraints, isolation, and psychotropic treatment.

\section{Conclusion}

Healthcare professionals in this study experienced a high incidence of workplace violence but with low levels of indi- 
vidual reporting. Respondents also reported that managerial actions and opportunities for mental support following incidents of violence were insubstantial. Although the response rate was high and participant demographics for victims and non-victims of violence were similar, this study only shows potential WPV trends. This is the result of limitations in sample size and study design. A major flaw in this study is the delineation and recruitment of participants, which ultimately reduces the generalizability of the study. Additionally, participants in this study gave their suggestive view of violent incidents from the past year, which could be influenced by recall bias. Finally, participants were recruited on a voluntary basis which could result in selection bias because healthcare professionals who experienced violence may have been more likely to respond to recruitment tactics.

Though this pilot study does not allow for absolute conclusions, it does suggest that the extension of support services following incidents should be mandated in order to mitigate the psychological effects of workplace violence and increase employee mental well-being. Moreover, inadequate consequences for attacker coupled with high dissatisfaction with managerial responses to episodes demonstrate the need for harsher penalties for perpetrators of violence as well as anonymous follow-ups of managerial actions. Most importantly, this study is valuable for researchers looking to design a WPV study that uses randomized sampling. Probability sampling uses non-discriminatory sampling techniques to create a sample that would have been representative of U.S. healthcare professionals. Regularity in quantitative studies is essential because it allows results to be applicable to the demographic as a whole as well as the accurate collection and statistical analysis of data.

All in all, workplace violence education and training should be required during the educational phase of healthcare professionals. Further examination of the relationship between individual reporting measures and managerial responses to violence is warranted. Additionally, assessment of educational interventions is needed to understand whether their implementation aids healthcare professionals in recognizing early signs of workplace violence and preventing future events.

\section{ACKNOWLEDGEMENTS}

This work was supported by the National Natural Science Foundation of China [No. 71573094] and the Fundamental Research Fund for Central Universities, HUST [No. 2013WZ024].

\section{CONFLiCTS OF INTEREST Disclosure}

The authors declare they have no conflicts of interest.

\section{REFERENCES}

[1] Workplace violence factsheet [Internet]. Washington, D.C.: Occupational Safety and Health Administration (OSHA); 2002 [Cited 2017 Feb]. Available from: www.osha.gov/OshDoc/data_General_F acts/factsheet-workplace-violence.pdf

[2] Sansone R, Sansone L. Patient aggression: Is the clinical practice setting safe? Innov Clin Neurosci. 2014; 11(11-12): 36-40. PMid:25621187.

[3] Wu S, Lin S, Li H, et al. A study on workplace violence and its effect on quality of life among medical professionals in china. Arch Environ Occup Health. 2014; 69(2): 81-88. PMid:24205959. https://doi.org/10.1080/19338244.2012.732124

[4] Hartley D, Doman B, Hendricks S, et al. Non-fatal workplace violence injuries in the United States 2003-2004: A follow back study. Work. 2012; 42(1): 125-135.

[5] Martini A, Fantini S, D'Ovidio MC, et al. Risk assessment of aggression toward emergency health care workers. Occup Med (Lond). 2012; 62(3): 223-225. PMid:22207453. https://doi.org/10.1 093/occmed/kqr199

[6] Cheraghi MA, Noghan N, Moghimbeygi A, et al. Analysis of intensive care nurses' workplace violence. Iran J Crit Care Nurs. 2012; 5(2): 87-94.

[7] Magnavita N, Heponiemi T. Violence towards healthcare workers in a public healthcare facility in Italy: A repeated cross-sectional study. BMC Health Serv Res. 2012; 12(1): 108. PMid:22551645. https://doi.org/10.1186/1472-6963-12-108

[8] Aytac S, Dursun S, Akalp G. Workplace violence and effects on turnover intention and job commitment: a pilot study among healthcare workers in Turkey. Eur Sci J. 2016; 12(10): 458-465.

[9] Farrell GA, Shafiei T. Workplace aggression, including bullying in nursing and midwifery: A descriptive survey (the SWAB study). Int J Nurs Stud. 2012; 49(11): 1423-1431. PMid:22770947. https: //doi.org/10.1016/j.ijnurstu.2012.06.007

[10] Kvas A, Seljak J. Unreported workplace violence in nursing. Int Nurs Rev. 2014; 61: 344-351. PMid:24847955. https ://doi.org/10 .1111/inr.12106

[11] Morphet J, Griffths D, Plummer V, et al. At the crossroads of violence and aggression in the emergency department: Perspectives of Australian emergency nurses. Aust Health Rev. 2014; 38(2): 194-201. PMid:24670224. https://doi .org/10.1071/AH13189

[12] Speroni KG, Fitch T, Dawson E, et al. Incidence and cost of nurse workplace violence perpetrated by hospital patients or patient visitors. J Emerg Nurs. 2014; 40(3): 218-228. PMid:24054728. https://doi.org/10.1016/j.jen.2013.05.014

[13] Lepping P, Lanka S, Turner J, et al. Percentage prevalence of patient and visitor violence against staff in high-risk UK medical wards. Clinl Med (Lond). 2013; 13(6): 543-546. PMid:24298096. https://doi.org/10.7861/clinmedicine.13-6-543

[14] Pompeii LA, Schoenfisch AL, Lipscomb HJ, et al. Physical assault, physical threat, and verbal abuse perpetrated against hospital workers by patients or visitors in six U.S. hospitals. Am J Ind Med. 2015; 58(11): 1194-12040.

Published by Sciedu Press 
[15] ILO, ICN, WHO, et al. Workplace violence in the health sector: Country case studies research instruments survey questionnaire (English). ILO/ICN/WHO/PSI. 2003: 1-14.

[16] Vellani KH. IAHSSF Crime and Incident Survey - 2017. Switzerland (GEN): International Association for Healthcare Security and Safety Foundation (IAHSSF); 2017 Apr. Report No. IAHSS-F CS-17. 8p.

[17] Fagerland M, Lydersen S, Laake P. Recommended confidence intervals for two independent binomial proportions. Stat Methods Med Res. 2011; 0(0): 1-31.

[18] Hahn S, Muller M, Hantikainen V, et al. Risk factors associated with patient and visitor violence in general hospitals: Results of a multiple regression analysis. Int J Nurs Stud. 2013; 50(3): 374-385. PMid:23102404. https://doi.org/10.1016/j.ijnurstu. 201 2.09.018

[19] Schablon A, Zeh A, Wendeler D, et al. Frequency and consequences of violence and aggression towards employees in the German healthcare and welfare system: A cross-sectional study. BMJ Open. 2012; 2(5): $\mathrm{e} 001420$
[20] Liu H, Zhao S, Jiao M, et al. Extent, nature, and risk factors of workplace violence in public tertiary hospitals in china: A cross sectional survey. Int J Environ Res Public Health. 2015; 12: 6801-6817. PMid:26086703. https://doi.org/10.3390/ijerph12060680 1

[21] Phillips J. Workplace Violence against health care workers in the United States. N Engl J Med. 2016; 374(17): 1661-1669. PMid:27119238. https://doi.org/10.1056/NEJMra1501998

[22] Williamson R, Lauricella K, Browning A, et al. Patient factors associated with incidents of agressioon in a general inpatient setting. J Clin Nurs. 2013; 23: 1144-1152. PMid:24341873. https: //doi.org/10.1111/jocn. 12294

[23] Sansone R, Sansone L. Disruptive office behaviors in the medical setting: Associations with other clinical phenomena. Innov Clin Neurosci. 2013; 10(3): 35-39. PMid:23630649.

[24] Oguagha AC, Yang QX, Chen J. Healthcare Professionals' workplace violence sightings in the United States [Chinese]. Med Soc. 2018; 3(13): 4-7. 